\title{
The role of senior managers' positive self-image in supporting MIS implementation
}

\author{
Nahid Izadpanah Mehrkish and Susan B. Grant \\ Brunel University London, Uxbridge, UK
}

\begin{abstract}
Purpose - Researchers have long been interested in how the psychology of senior managers affects their behaviours. This paper aims to present the results of a questionnaire into how positive self-image influences how well senior managers in UK manufacturing organisations support the implementation of management information system (MIS). This study developed two scales, one to measure senior managers' attitudes and the other to measure support of MIS implementation. It also sought to investigate the impact of senior managers' positive self-image on their support of MIS implementation in UK manufacturing organisations.

Design/methodology/approach - The authors tested the hypotheses on a data set of 400 senior managers from UK manufacturing organisations. Two unidimensional scales to measure senior managers' attitude and support level towards MIS implementation were developed. Exploratory factor analysis (EFA) was used to validate the scales. The study also examined the impact of senior managers' positive self-image on their attitude and support from the perspective of UK manufacturing organisations by using structural equation modelling.
\end{abstract}

Findings - The study found that senior managers' positive self-image is a significant contributing factor to their attitude. Also, senior managers' attitude has a strong positive impact on their support in the MIS implementation process. A strong mediating relationship was found to exist between senior managers' positive self-image and support through their attitude towards MIS implementation.

Originality/value - Although past literature has examined the importance of senior managers' attitude and support in successful MIS implementation, there has been no specific scale around management support and attitude towards MIS implementation developed to date. Thus, a contribution of this study is its development of two new scales based on a survey of senior managers of UK manufacturing organisations. The scales can be used to evaluate senior managers' perception towards MIS implementation and the support they are willing to give whilst implementing MIS. Another contribution of this study is the analysis of positive self-image via item-parcelling which improves model efficiency and provides more stable estimates of the construct.

Keywords Executives, Information systems, Top managers, Psychological attributes, MIS implementation, Positive self-concept

Paper type Research paper

\section{Introduction}

An information system (IS) is "a set of components that collect, process, store and distribute information" to enable decision-making and control in an organisation (Laudon and Laudon, 2020, p. 48) or supply chain (Grant, 2016). Management, organisations and information technology (IT) are the three components of IS (Laudon and Laudon, 2020). IT is the hardware and software an organisation needs to use to achieve its business objectives (Bessen, 2017). The first emergence of management information systems (MIS) dates back to the 1960s through the teaching and writing of researchers (Wagner and Newell, 2011). Laudon and Laudon (2020) defined MIS as the field of IS which deals with both behavioural
Senior managers' positive selfimage
Received 21 January 2021 Revised 15 April 2021 25 May 2021 Accepted 16 June 2021 
and technological issues surrounding using IS (its development, use and impact) by managers and employees. MIS plays a role in different aspects of an organisation such as operations, finance, decision-making, project management, competitive advantage and human resources (Galliers and Currie, 2011). MIS is designed to help managers and employees by processing very large quantities of information so managers can make better decisions (Vieru and Rivard, 2014), which can help organisations keep their profitability up.

Significant numbers of organisations are not able to operate successfully and adequately without the availability of MIS. This is due to a growing interdependence between an organisations' ability to implement their strategies and achieve their goals and their ability to use MIS (Saunders and Brynjolfsson, 2016). Organisations use MIS applications to improve their performance and decision-making. These applications include enterprise systems, customer relationship management (CRM), knowledge management, e-commerce applications, etc. (Chatterjee et al., 2020). Enterprise systems, also known as enterprise resource planning (ERP), are a set of software modules and a central database through which different functional areas of an organisation (i.e. finance, human resources, sales and marketing, manufacturing and production) can share data (Mullins and Cronan, 2021). systems, applications, and products and Oracle are examples of ERP software that are used commercially. The process of MIS implementation can involve changes in hardware, software, telecommunications and databases (Laudon and Laudon, 2020). It is predicted that global investment in IS will grow to US\$6.2tn in 2020 (IDC, 2018). This shows that more companies will invest in IS and if companies to implement IS, they can lose their competitive advantage. The term "MIS" will be used solely referring to ERP, CRM and supplier relationship management (SRM) because they are the most commonly used systems in organisations (Cruz-Jesus et al., 2019; Guerola-Navarro et al., 2021; Mullins and Cronan, 2021).

Although in the past manufacturing organisations have adopted various methodologies to improve their operations management such as ERP, CRM and SRM, and more recently industry 4.0, many manufacturing organisations are still at relatively early stages of implementing such technologies (Buer et al., 2020). Therefore, there is a need for further investigation of MIS implementation in manufacturing organisations. Many IS projects are considered a failure if they do not achieve organisation goals and finish on time within approved budget (Amid et al., 2012). This shows that organisations are struggling to implement MIS successfully. Studies (Somers and Nelson, 2001; Ehie and Madsen, 2005; Kappelman et al., 2006; Iacovou and Nakatsu, 2008; Agarwal and Garg, 2012; Almajali et al., 2016; Ali and Miller, 2017) show that senior managers are one of the most important factors in successful MIS implementation as they can assist in providing essential resources such as IT, facility, human resources and capital (Young and Jordan, 2008).

Extensive research has been done over the past 40 years on senior managers. Researchers (Hambrick and Mason, 1984; Hambrick, 2007; Finkelstein et al., 2009; Wang et al., 2016) have long tried hard to understand how senior managers' characteristics influence their strategic choices. Finkelstein et al. (2009) argued that senior managers' characteristics (i.e. tenure, experience, education and personality) form their values and beliefs, which influence their decision-making and behaviours. The detailed study by Wang et al. (2016) investigated the role of senior managers in firm performance based on upper echelon theory (UET) and found that senior managers' characteristics such as formal education, career experience and positive self-image have a significant impact on their strategic actions, which may have an impact on senior managers' actions towards MIS implementation. This suggests that senior managers' decision-making is influenced by positive self-image because positive self-image impacts their perception of available 
strategic actions. Consequently, senior managers will allocate essential resources for a successful MIS implementation.

The study by Hiller and Hambrick (2005) identified the lack of understanding of the implications of senior managers' personalities in relation to their decision-making (Hiller and Hambrick, 2005). Understanding how senior managers make decisions provides insights on the reasons they might not be supportive of MIS implementation, which can lead to a failure of the implementation. In addition, there was a lack of a grounded theory to measure the concept of positive self-image until Judge et al. (2003), in their influential study, proposed core self-evaluation construct (CSE) as a valid construct to measure positive selfimage. Different authors use different terms referring to the concept of "positive self-image" including "positive self-regard" (Finkelstein et al., 2009); "positive self-concept" (Seo et al., 2019); "personality traits" (Wang et al., 2016). In this paper, we are going to use the term "positive self-image", which refers to the extent that senior managers positively assess themselves and their ability to influence their organisations. Studies related to positive selfimage show that positive self-image is positively related to the strategic actions of a firm (Wang et al., 2016), job satisfaction (Judge et al., 2003), job performance (Judge et al., 2003), life satisfaction (Judge et al., 2003), speed of a firm's strategic decision-making (Hiller and Hambrick, 2005), centralisation of a firm's strategic decision-making (Hiller and Hambrick, 2005), task motivation and performance of a firm (Erez and Judge, 2001) and firm's performance (Hiller and Hambrick, 2005). These findings highlight the importance of positive self-image in the upper echelon field and show that senior managers' positive selfimage impacts their choices (Hambrick, 2007). Therefore, the significance of these findings is that they highlight that senior manager who have high positive self-image will engage more in high-risk strategic choices but have not directly investigated the impact of self-image on MIS implementation.

Although the concept of CSE was introduced, some researchers only use single elements of the construct [i.e. self-esteem, generalised self-efficacy, emotional stability and locus of control (LOC) (Judge et al., 2002)]. These elements are four aspects of the broader concept of a positive self-image. A study by Ndofirepi (2020) makes no attempt to investigate the relationship between senior managers' self-image and their entrepreneurial intentions. However, it was found that internal LOC has a significant impact on entrepreneurial intentions. Lam et al. (2007) found that self-efficacy has a positive impact on behavioural intention. Xu et al. (2020) showed that internal LOC impacts innovative behaviour both directly and indirectly. Boone and Hendriks (2009) found that senior management team (SMT) LOC diversity has no significant impact on SMT's collaborative behaviour and information exchange. These findings show that senior managers' behavioural intention is influenced by their positive self-image. The single elements of self-efficacy and LOC impact senior managers' behaviour, but they only show a narrow glimpse of the broader concept of a positive self-image. Positive self-image provides more potent predictions of senior managers' behaviours than the individual elements (Judge et al., 2002). It is, therefore, important to investigate positive self-image to get more information on senior managers' behaviours towards MIS implementation.

A central theoretical model on the influence of senior managers on firm behaviour perceived to be of value to this research is UET (Hambrick, 2007; Hambrick and Mason, 1984). The basic logic of UET is that senior managers make their choices based on their experiences, values and positive self-image (Hambrick, 2007) and these choices impact firms' performance (Hambrick and Mason, 1984). Mainly, this research focusses on senior managers' positive self-image, which influences how senior managers process information about the environment and their capabilities. Senior managers' comprehension and 
interpretation of the information impact their decisions (Finkelstein et al., 2009). This construct gives a comprehensive picture of how senior managers perceive their surroundings and their corresponding behaviour (Finkelstein et al., 2009). This picture shows the reasons behind senior managers' choices to either support MIS implementation or not. When a senior manager has a favourable attitude towards MIS implementation because of his perceptions, he will manifest his favourable attitude by supporting it.

A meta-analysis of this growing area of literature expands the understanding of the relationship between positive self-image and their support. Senior managers' attitudes and support have been studied before (Jarvenpaa and Ives, 1991; Khan et al., 2013; Roumani et al., 2017). For example, in the ground-breaking study of senior management support by Jarvenpaa and Ives (1991), they found that senior managers' support positively impacted on the progressive use of IT within the firm. Their work is significant because they conceptualised the construct of senior managers' support as senior managers' involvement and participation, which refers to how critical they think IT is for their firms' survival and how much time and energy they are willing to invest in IT-related matters, respectively. This suggests that the concept of support not only involves senior managers' actions but also related to their psychological state and attitude. Their sample size was limited to 57 senior managers, which affected the confidence in the findings. Roumani et al. (2017) found that adoptors' attitude and intention is influenced by the trust in the IT system. However, there is an overlap in items of the construct of attitude proposed by both Roumani et al. (2017) and Jarvenpaa and Ives (1991) which limits the statistical reliability and validity of the proposed construction and impacts the prediction of the measure (Bozeman and Perrewé, 2001). Khan et al. (2013) showed that senior management support has a positive significant impact on IS performance. The proposed construct of support shows statistically sufficient reliability and validity. However, it is only limited to senior management support in the context of ISs operations. Senior managers' support of MIS implementation which gets us to operations has not yet been clarified. Their sample size of only 47 limited the confidence in the findings. This limitation has brought about the need to conduct a large-scale study. Moreover, there is a gap in the literature for a reliable and valid construct to measure senior managers' attitude and support towards MIS implementation.

A contribution of this research is to analyse how closely senior managers' attitudes are linked to UET, specifically, the impact of self-image on the attitude of senior managers. There are two main reasons that this topic has been overlooked. Firstly, senior managers are often reluctant to fill in lengthy questionnaires (Hambrick, 2007; Finkelstein et al., 2009). Secondly, the average response rate for studies involving senior management is $36.1 \%$ (Baruch, 1999), comparing to $55.6 \%$ of non-senior manager respondents, which makes the findings more limited due to the smaller sample size. Access to senior managers at the board level is limited to the point that in a recent study by Hill et al. (2019), they proposed a video metrics method to measure the characteristics of senior managers at the board level. A larger sample size allows a more accurate estimate of the effect and easier assessment of the representativeness of the sample to generalise the results (Dichev and Skinner, 2002). In today's world, it is inconceivable that large organisations would need to implement MIS to maintain their supply chain operations (Grant and Preston, 2019). There are various factors that influence the decision to implement MIS including financial resources (Amid et al., 2012), rewards such as improvements in business process, customer responsiveness and strategic decision-making (Shaul and Tauber, 2013), security risks (Jha and Pal, 2016) and poor system quality and user dissatisfaction (Poba-Nzaou et al., 2008). This study is focussed on how senior managers' positive self-image influences their level of support towards MIS implementation. Based on the literature discussed above, we hypothesise that 
positive self-image influences managers' attitude towards MIS implementation and their attitude has a direct positive impact on the level of support given to MIS implementation. The paper structured in the following way: we start by outlining the key theory, our conceptual framework and generating hypotheses. Our findings are presented before we conclude with implications to theory and practice.

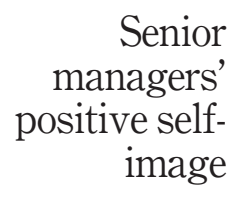

\section{Theory, model and hypotheses}

UET is one of the most influential theories in the upper echelon field and was first introduced by Hambrick and Mason (1984). The theory is significant because it identifies the underlying reasons for the way organisations act in terms of their strategic choices and efficiencies, which provides a better understanding of the reasons behind organisations performance and the things they do. This understanding enables organisations to improve their performance and consequently keep up their profitability. UET has been used to study firms' strategic actions and performance (Wang et al., 2016). López-Muñoz and EscribáEsteve (2017) state that the UET suggests that organisational objectives and outcomes are a critical reflection of the organisations' senior managers' characteristics. This is because organisational objectives are mainly decided by senior managers. Senior managers make decisions based on their characteristics including attitudes, demographics, values, beliefs, functional experiences, professional competencies and educational background (Hambrick, 2007). The UET is a broad theory that emphasises the relation between procedures, characteristics and senior management support structures (Hiebl, 2014) because senior managers make strategic choices based on their perceptions, which are shaped by their values, which are influenced by their characteristics.

Hiebl (2014) also states that the theory focusses on the organisations' strategic decisions and their performances whilst also including strategic renewal, internationalisation, acquisitions and mergers. MIS implementation can be considered as a strategic choice, which is defined as "complex and of major significance to the organization" (Hambrick and Mason, 1984, p. 194) because MIS implementation is complex and often involves fundamental organisational changes (Amid et al., 2012). Abatecola and Cristofaro (2018) maintain that the theory indicates that the organisational performance and strategic outcomes are partially predicted by managerial background characteristics, i.e. the managers' values and cognitive basis for the managers' values. Besar et al. (2017) agreed and added that three basic principles that underlie UET include cognitive bias and values which are the reflection of the strategic decisions, knowledge and values which conform to particular observable characteristics such as experience or training and the outcomes related to the observable characteristics of the senior managers. These studies highlight that senior managers' positive self-image impacts their attitude through their values and perceptions. Our research question related to UET is, therefore, "To what extent, does senior managers' positive self-image impact their attitude towards MIS implementation"?

Theory of planned behaviour (TPB) is the most influential conceptual framework used to study the behaviour of an individual and was proposed by Ajzen (1991) and Ajzen and Fishbein (1977). The theory demonstrates predictors of a complex concept of an individual's intentions to perform a behaviour with high accuracy (Ajzen, 1991). According to this theory, a person's intention to perform a specific act or their behavioural intention is associated with their attitude towards the behaviour. TPB is an extension of the theory of reasoned action (TRA) (Ajzen and Fishbein, 1977; Ajzen and Fishbein, 1975). TRA explains that attitude towards a behaviour, subjective norm and perceived behavioural control are predictors of one's intention to perform a behaviour. Ajzen (1991) validated how the theory predicts the behaviour of an individual by analysing activities in nine different studies. He 
found that there is a significant relationship between attitude and behaviour. The study of Ledgerwood and Shrout (2011) highlighted the importance of mediation analysis arguing that mediation analysis gives a better understanding of the underlying process of cause and effect. The studies reviewed above indicate that senior managers' intention to support MIS implementation is predicted by their attitude towards MIS implementation and their positive self-image impacts their attitude. This prompts a second research question: "To what extent does senior managers' attitude mediate the relationship between their positive self-image and support”?

\section{Positive self-image and its effects on senior managers' attitude}

Personality is conceptualised from a variety of theoretical perspectives. These perspectives and approaches have made a unique contribution in this field of interest where there is a need to determine how personality traits predict the job performance of an individual. The five-factor model (FFM) is one of the prominent paradigms of personality traits (Costa and McCrae, 1992). FFM affects how an individual processes information about their surroundings, organisations and capabilities (Finkelstein et al., 2009) which consequently impacts his or her behaviour. These five factors are neuroticism, extraversion, openness to experience, agreeableness and conscientiousness. Neuroticism is the opposite of emotional stability, where an individual has poor emotional adjustment and has a tendency to be more anxious and depressed (Barlow et al., 2014). Extraversion demonstrates how sociable and positive an individual is (Wilt and Revelle, 2009). Openness to experience refers to an individual's tendency to be creative and flexible. An individual who scores high on agreeableness is kind and trustworthy. Conscientiousness refers to the tendency to be achievement striving (Costa and McCrae, 1992). FFM has received little attention in UET research because senior managers are often reluctant to fill in lengthy questionnaires to operationalise the FFM (Hambrick, 2007). Therefore, UET studies focussed on individual personality constructs (e.g. LOC, self-esteem, self-efficacy and emotional stability) to demonstrate the positive self-image of an individual (Hiller and Hambrick, 2005). Quantifying these constructs assists researchers to differentiate individuals by their pattern of thoughts, feelings and actions (Costa and McCrae, 1992). These four well-studied constructs have significant conceptual similarities and the area of their similarity make up the underlying evaluation a person makes of one-self, which refers to a positive self-image. Positive self-image brings all four constructs together and leads to the more potent prediction of a person's behaviours than the individual variables (Hiller and Hambrick, 2005).

Because self-image is important in influencing a senior managers' attitude towards implementing MIS, it is worth defining the concept of self-image. Seo et al. (2019) defined self-image as a combination of various beliefs one holds about oneself. Their study demonstrated that the notion of self-image is dissimilar to self-awareness which embodies the extent of knowledge one has about oneself. Farrar et al. (2015) contributed to the field by highlighting that the beliefs of others about oneself also contribute to the process of selfconstructing the beliefs about oneself. These studies indicate that senior managers' selfimage encompasses and consolidates both their own beliefs about themselves and others' beliefs about them, which shape their attitude towards MIS implementation.

Peixoto and Almeida (2010) and Di Fabio and Kenny (2016) found that there are multiple factors that contribute to the formulation of self-images, such as ideal self and self-esteem. The study of Weng and McElroy (2010) concluded that age, education and media are other factors that facilitate a person in framing their self-image. In contrast, the study of Evert et al. (2018) considered culture, gender, relationship and appearance to be major 
determinants that contribute to formulating a self-image about one oneself. Additionally, the study of Seo et al. (2019) highlighted that there are several sub-factors such as LOC and selfesteem which assist an individual in developing either a productive or negative self-image about oneself. The research of Farrar et al. (2015) contemplated that self-efficacy and emotional stability are two major determinants that contribute to establishing a positive and negative self-image of oneself. It can be seen that the literature defines positive self-image in many ways, therefore, this demonstrates why researchers have used different constructs to measure the same concept, which indicates the complexity of positive self-image. This study is using positive self-image to include all four variables mentioned above ( $L O C$, self-esteem, self-efficacy and emotional stability) and predict senior managers' attitudes towards MIS implementation.

In their ground-breaking study of a positive self-image, Judge et al. (2003) introduced the CSE as an effective approach or framework to measure positive self-image. because it uses the four underlying personality traits of self-esteem, generalised self-efficacy, emotional stability and $L O C$. Self-esteem demonstrates how an individual evaluates his self-worth (Rosenberg, 1965). Self-efficacy refers to an appraisal of an individual's ability to perform successfully in situations. Emotional stability is one's tendency to feel safe and calm. Finally, $L O C$ is a person's belief that desired outcomes are a consequence of one's behaviour not from fate (Judge, 2002). CSE is a method to measure how an individual assesses himself and his relationship with the environment (Judge et al., 2003). These four traits are highly correlated (Judge et al., 2003). Their work is significant to the field because they proposed a 12-item scale which connects all four well-studied concepts of positive self-image and enables researchers to quantify senior managers' positive self-image. CSE has been validated and identified in several studies (e.g. Gardner and Pierce, 2010), but its relevance to senior managers and their attitudes has not been examined widely. In this study, we used CSE as a tool to measure positive self-image because it provides a more potent predictor of senior managers' attitude towards MIS implementation, which consequently leads to a better understanding of the underlying reasons of senior managers' favourable attitude towards MIS implementation. Senior managers' attitude significantly impacts the success of MIS implementation because if they have a favourable attitude towards MIS implementation, they will provide resources for a successful implementation.

Barrick et al. (2003) and Judge and Ilies (2002) supported the opinion that senior managers with a more positive self-image are more confident and optimistic, so it could be assumed that they are more confident in making decisions with high risk. Chatterjee and Hambrick (2011) argued that such narcissism has a positive influence on mergers, research and development expenses and capital expenditures. This is because a senior manager assesses risk based on his or her confidence. According to Hiller and Hambrick (2005), an individual with a healthy amount of narcissism can function successfully because it gives him or her secure self-esteem to survive everyday life. Thus, we predict a positive association between senior managers' positive self-image and attitude towards MIS implementation. MIS implementation requires a significant amount of money and time investment (Amid et al., 2012), therefore, a more confident senior manager is more likely to make a decision to support MIS implementation. Senior managers' positive self-image influences their choice to support implementation.

Similarly, Finkelstein (1992) argued that top management team (TMT) characteristics predict their strategic behaviour. Positive self-image as one of the managers' characteristics shows how a person appraises his self-worth and capabilities. It is conceptualised as a higher-order construct. Personality theorists (Cattell, 1965) argued that positive self-image as a fundamental trait has a strong association with attitude. Experiences, values and 
personalities impact on an individual's information processing behaviour (field of vision, selective perception, interpretation) (Hambrick, 1984). These findings demonstrate the underlying factors which play a part in developing an individual's behaviour. Therefore, there is a strong association between senior managers' attitude towards MIS implementation and their positive self-image.

Judge et al. (1997) proposed that an individual takes actions because of their CSEs which may indicate that a senior manager having a certain self-image will undertake to support MIS implementation. Brown et al. (2007) suggested that an individual's positive self-image impacts his commitment. Kamer and Annen (2010) also demonstrated that individuals with a more positive self-image are more committed to the goals they set. People with a high positive self-image are more committed to pursuing opportunities that are present to them (Johnsen et al., 2008). These findings suggest that a positive self-image increases senior manager's commitment resulting in greater support of MIS implementation.

Erez and Judge (2001) argued that a person with a higher positive self-image has increased motivation to perform tasks, which can infer that they will have more motivation to support innovations and new IS projects. Individuals with high positive self-image view their circumstances more positively and are less sensitive to negative information (Chang et al., 2012). Therefore, they are more positive to the challenges of new MIS implementation and more committed to supporting it. Given the significance of the findings above, we propose as follows:

H1. A positive self-image is positively related to the attitude towards MIS implementation.

\section{Senior managers' support towards management information system implementation}

Attitude can be described as a person's disposition to react well or badly to an individual, an item, an organisation or an event or to the way that an individual appraises a behaviour (Ajzen and Fishbein, 1977). In their wide-ranging study of individual behavioural intention to adopt IT, Lam et al. (2007) investigated the impact of self-efficacy, attitude, perceived IT beliefs and subjective norm on the intention to adopt IT. They found that a positive attitude has a positive impact on the intention to adopt IT. They also showed that the productive outcome of any manufacturing project depends on the integrity and commitment of senior management that drives the workforce towards the success of the project (Elbanna, 2013). In addition, Lin (2010) demonstrated that the optimistic attitude of senior management towards themselves is of vital importance to maintain optimum productivity during the execution of projects as it ensures the required level of commitment and determination of the workforce for the project's success. These studies show the underlying influence of senior managers' attitudes on their support towards IS projects. The studies, thus far provide evidence that senior managers manifest their favourable attitude towards MIS implementation by supporting it through their commitment and allocation of required resources for the implementation process.

The intention is defined as an individual's attempt to perform a behaviour (Fishbein and Ajzen, 2010). According to Lam et al. (2007), behavioural intentions have a positive correlation with actual behaviour. The seminal TPB (Ajzen, 1991) suggests that the more positive attitude an individual has towards a behaviour, his intention to perform the behaviour is stronger. In the context of this study, senior managers' intention to implement MIS is determined by their perceptions about the positive and negative results of implementing MIS (attitude). 
Kwok and Gao (2006) argued that an individual is more likely to perform a behaviour when he or she possesses a positive attitude. A favourable attitude is also likely to encourage employees to adopt and use an innovation (Quazi and Talukder, 2011). These findings are important because they highlight a causal relationship between attitude and support, which shows why senior managers show different degrees of support towards MIS implementation. The literature (Tandon et al., 2020) suggests that a positive attitude is significantly correlated with the readiness to participate in a given behaviour. Tandon $e$ t al. (2020) study is thorough because they also investigated the mediation effect of attitude between reasons and intentions. Mediation analysis gives a better understanding of the underlying mechanism of senior managers' support towards MIS implementation.

Therefore, we propose as follows:

H2a. Attitude towards MIS implementation is positively related to supporting MIS implementation.

$H 2 b$. Senior managers' attitude mediates the relationship between senior managers' positive self-image and their support.

Figure 1 graphically depicts the set of relationships, inner and outer model.

\section{Methodology}

Sample

Our sample consists of 400 senior managers in UK organisations selected from the population of firms operating in manufacturing industries. Cluster sampling was used because our subjects are fragmented over large geographical areas (Davis, 2005). All the

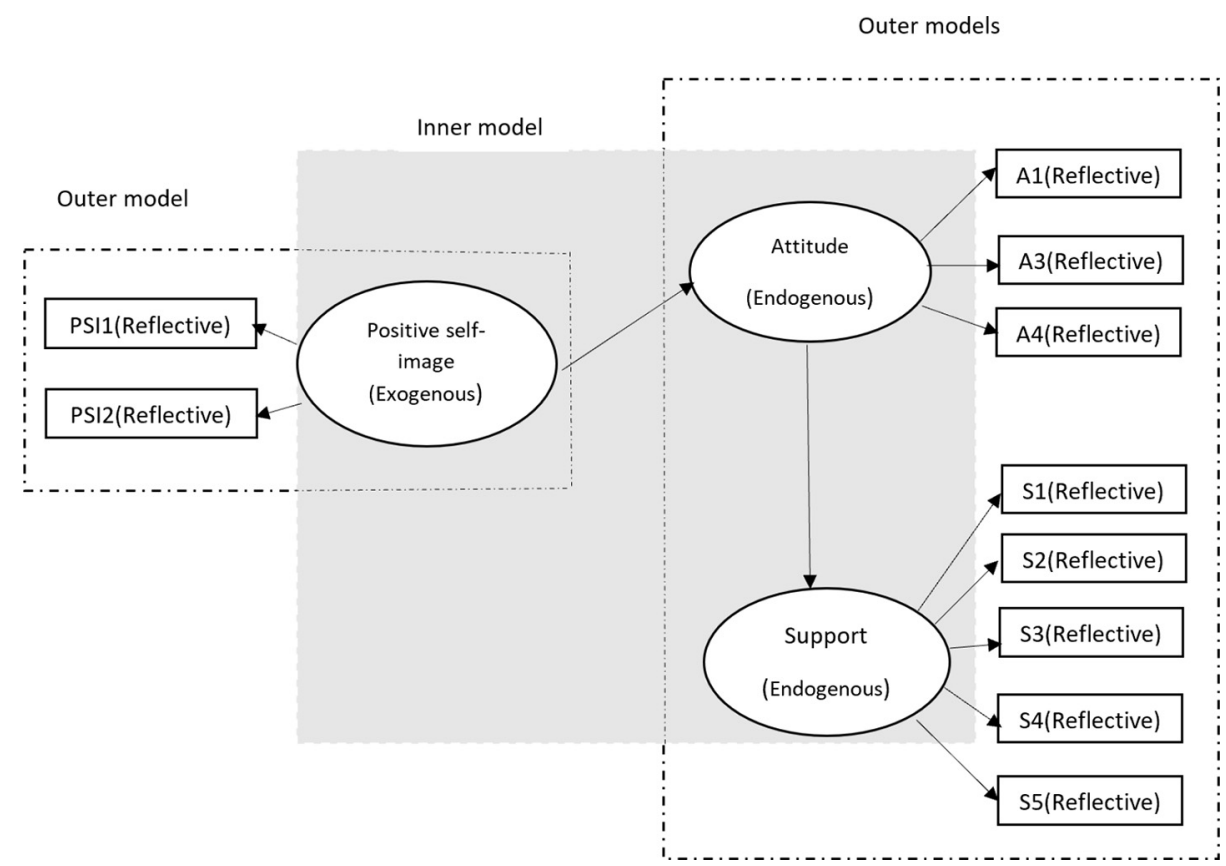

Figure 1. Theoretical model of this study

positive selfimage

Senior managers' image

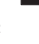


manufacturing organisations in the UK were divided into 14 clusters based on their location and then participants were chosen randomly in each cluster. In total, $70 \%$ of participants were male, $29 \%$ were women and $1 \%$ were non-binary. Participants' age ranged from 20 to 64 years, with a mean of 41.5 and a standard deviation of 5.31 years. Almost three-quarters of the participants were from companies that employ less than 1,000 employees. In total, $23 \%$ of participants were from organisations that employ between 1,000 to 10,000 employees and just $2 \%$ of participants were from companies with more than 10,000 employees. The online survey-questionnaire was sent to participants and data was collected over 7 days in July 2020. To ensure confidentiality, we did not collect participants names.

\section{Measures}

A 12-item measure that optimally taps the central CSE constructs developed by Judge et al. (2003) was used. (Gardner and Pierce, 2010) argued that this measure is better to use when participant's time is limited and because senior managers' time is very valuable, we chose the direct approach to measure CSE. The validity of this scale was upheld by researchers (Gardner and Pierce, 2010). The 12-item measure was modified to make sure that we could distinguish between senior managers with high CSE and those with very high CSE, so we followed the recommendation by Hiller and Hambrick (2005). Some of the items were reworded to evaluate higher CESs more precisely. For instance, the item, "When I try, I generally succeed" might be reworded as, "When I try, I almost always succeed". CSEs is a unidimensional scale (Judge et al., 2002) and the itemparcelling method can be used. Two parcels of items (positive dimension of CSE and negative dimension) were created based on their item content (Landis et al., 2000). The internal consistency reliabilities and scree test results confirm the reliability of the parcels (Table 1). The minimum standard for reliability (Cronbach's alpha $>0.6$ ) was reached for both parcels (Kishton and Widaman, 1994). Item parcelling improves commonality across indicators and improves modelling efficiency, providing more stable estimates and fit the data better (Matsunaga, 2008).

Four measures were used to measure the senior manager's attitude. The participants were asked to evaluate four statements on a five-point Likert scale. We calculated the mean to create the "attitude" variable. An item-based approach (Matsunaga, 2008) was chosen because the number of observed variables is less than 6 . Support was measured by five measures. The senior managers evaluated five statements on a five-point Likert scale. We took the average to create a value for the "support" variable.

\section{Analyses and results}

\section{Measure validation}

Unidimensionality was assessed by means of confirmatory factor analysis (CFA) (Anderson and Gerbing, 1988) with results that suggested a good fit (Table 2). We used IBM SPSS AMOS 26 software to perform the CFA. We evaluated the assumptions of multivariate normality and linearity using SPSS 26. Using box plots and Mahalanobis distance, we observed no univariate or multivariate outliers; there were no missing data.

The reliability of the measures is satisfactory because for all the measures the Cronbach's alpha is higher than 0.5 (Cronbach alpha for attitude, support scale and positive self-image

Table 1.

Number of items; internal consistency reliability; scree test

\begin{tabular}{lccc}
\hline Parcel & Number of items & Internal consistency reliability & Scree test \\
\hline PSI1 & 6 & 0.631 & 1 \\
PSI2 & 6 & 0.624 & 1 \\
\hline
\end{tabular}


(PSI) equalled 0.598, 0.751 and 0.705, respectively). Additionally, all items load on their hypothesised factors and the estimates are positive and significant.

Any scale should be validated to ensure that it measures what it is supposed to measure. The validity of construct investigates the relationship of one variable with other variables (Pallant, 2011). Exploratory factor analysis (EFA) was used to measure the validity of the measurement scales. In this study, factor analysis was conducted via principal components analysis (PCA) using varimax rotation (Eignevalues $>1$; suppress factor loadings $<0.3$ suggested by Hair et al., 2010). Bartlett's (1954) test of Sphericity and KaiserMeyer-Olkin (KMO) value of 0.6 recommended by Kaiser (1970-1974) were used to determine the suitability of data to be factorised. Screeplots were inspected to investigate clear breaks in components.

Table 2 shows the EFA for senior managers' attitude towards MIS implementation, The Bartlett's test was significant $(\phi<0.001)$ and the KMO measure of sampling adequacy was 0.678 , which is above the acceptable level of 0.6. All the items loaded onto a single factor explaining $47.8 \%$ of the variance. Attitude 2 did not meet the minimum value of 0.50 for factor loadings (Hair, Risher, et al., 2019), it was removed (Table 2). The final measure consists of 3 scale items.

After removing Item 2, the model was a rerun. The overall KMO was 0.659; the communality was above 0.50 and the rotated matrix was left with three factors or constructs. In total, $61.47 \%$ of the total variance is explained by all items. The reliability of the construct was recalculated and Cronbach's alpha was 0.676 .

KMO value was 0.791 and Bartlett's was less than 0.001 . In total, $50.3 \%$ of the total variance is explained by all items loading on one factor with factor loadings between 0,562 and 0.747. All items et a minimum value of 0.50 for factor loadings (Hair, Risher, et al., 2019) However, inspecting the communality matrix which measures of how much the model explained each variable. Values below 0.5 should be eliminated (Hair, Gabriel, et al., 2019). Communalities ranging from 0.316 to 0.573 and support 4 with a communality value of 0.316 was eliminated. The final measure consists of 4 scale items.

After Item 4 was removed, the model was a rerun. The overall KMO was 0.76 ; the commonality was above 0.50 and the rotated matrix was left with four factors or constructs. The reliability of the construct was recalculated and Cronbach's alpha was 0.754 .

The squared multiple correlations (SMC) are also provided in Table 3; PSI2 (0.501) and PSI1 (0.245) have the highest and lowest, respectively. An interpretation is that the construct attitude accounts for $38.6 \%$ of the variance in Attitude 1. Because of the good-fit indices, no post hoc modifications were indicated from the analysis and residual analysis did not indicate any problems (all items less than the cut point of 2.58 (Byrne, 2001) (Tables 4-5).

Descriptive statistics and correlations are reported in Table 4. The model depicted in Figure 1 was tested using structural education modelling. We chose maximum likelihood

\begin{tabular}{lccc}
\hline Measure & Mean & SD & $\begin{array}{c}\text { Factor } \\
\text { loading }\end{array}$ \\
\hline A1 & 2.40 & 0.996 & 0.736 \\
A2 & 3.23 & 0.950 & 0.368 \\
A3 & 2.13 & 0.799 & 0.780 \\
A4 & 2.13 & 0.799 & 0.793
\end{tabular}

Notes: KMO 0.678. Bartlett's $<0.001$. Variance explained $47.8 \%$

Table 2. Scale items, descriptive statistics and factor loadings for attitude $(\mathrm{N}=400)$ 
parameter estimation over other estimation methods (generalised least squares, unweighted least squares, scale-free least squares, asymptotically distribution-free) because the data were distributed normally (Byrne, 2001). The construct reliability for the constructs of attitude and support were 0.713 and 0.721 , respectively. The average variance extracted for attitude and support constructs were 0.45 and 0.46 , respectively. Thus, the requirements for convergent validity and discriminant validity of the constructs were satisfied. The newly developed unidimensional scales of attitude and support qualified the tests of internal consistency, convergent and discriminant validity.

\section{Testing the hypotheses}

This section examines $H 1$. To address $R Q 1$, which concerns the impact of positive selfimage on senior managers' attitude towards MIS implementation. Positive self-image

Table 3.

Scale items, descriptive statistics and factor loadings for support $(\mathrm{N}=400)$

\begin{tabular}{lccc}
\hline Measure & Mean & SD & $\begin{array}{c}\text { Factor } \\
\text { loading }\end{array}$ \\
\hline S1 & 2.23 & 0.831 & 0.763 \\
S2 & 2.21 & 0.807 & 0.720 \\
S3 & 2.11 & 0.844 & 0.789 \\
S5 & 2.17 & 0.808 & 0.760
\end{tabular}

Notes: KMO 0.76. Bartlett's $<0.001$. Variance explained $57.51 \%$

\begin{tabular}{lc}
\hline Observed variable & Estimate \\
\hline PSI1 & 0.245 \\
PSI2 & 0.501 \\
MIS implementation value (A1) & 0.386 \\
Efficiency from MIS implementation(A3) & 0.426 \\
Organisational benefits (A4) & 0.469 \\
Readiness to put Effort (S1) & 0.401 \\
Effective management strategies (S2) & 0.411 \\
Favouring MIS implementation(S3) & 0.476 \\
Active involvement (S5) & 0.420 \\
\hline
\end{tabular}

\section{Table 5.}

Standardised and unstandardised coefficients for CFA

\begin{tabular}{llccr}
\hline Observed variable & Latent construct & $\beta$ & $\mathrm{B}$ & SE \\
\hline PSI1 & PSI & 0.495 & 0.796 & 0.103 \\
PSI2 & PSI & 0.708 & 1.000 & \\
MIS implementation value (A1) & Attitude & 0.623 & 1.000 & \\
MIS implementation cost (A2) & Attitude & 0.224 & 0.343 & 0.085 \\
Organisational benefits (A4) & Attitude & 0.685 & 0.882 & 0.082 \\
Readiness to put effort (S1) & Support & 0.631 & 1.000 & \\
Effective management strategies (S2) & Support & 0.635 & 0.977 & 0.095 \\
Favouring MIS implementation(S3) & Support & 0.707 & 1.138 & 0.103 \\
Active involvement (S5) & Support & 0.649 & 1.000 & 0.095 \\
\hline
\end{tabular}


significantly impacts senior managers' attitude towards MIS implementation $(0.869, p<$ 0.001 ) confirming $H 1$. Also, we examined the mediating role of senior managers' attitudes to address RQ2. $H 2 a$ and $H 2 b$ were tested. The results also confirm $H 2 a$ about the positive effect of senior managers' attitude on their support towards MIS implementation $(0.931 ; p<$ $0.001)$. $H 2 b$ was tested using user-defined estimands and the results supported $H 2 b$ (1.65, $p=0.009)$ (Table 6-8).

Figure 2 illustrates the structural equation model. This model had a good fit based on commonly-used fit indices as follows: Comparative Fit Index (CFI) $=0.973$ (within the excellent range fit (Bandalos's, 2014); root mean square error of approximation (RMSEA) = 0.043; Tucker-Lewis fit index $(\mathrm{TLI})=0.964$; Goodness of Fit Index $(\mathrm{GFI})=0.969$ and all factor loadings were statistically significant. These values indicate a good fit between the model and the observed data. Standardised parameter estimates are provided in Figure 2; unstandardised estimates are shown in Table 3. We did not conduct post hoc modifications because of the good fit of the data to the model.

\section{Discussion}

In this study, we designed two new unidimensional scales to measure two important constructs of senior managers' attitude and support towards MIS implementation in a manufacturing setting. Our findings are aligned with the findings of previous research. Our study sought to explore the impact of positive self-image on the attitude of senior managers towards MIS implementation. Our findings provide strong support for the research framework developed in this paper We found that positive self-image has a direct positive impact on senior managers' attitudes, consistent with the literature (Barrick et al., 2003) suggesting that positive self-image impacts senior managers' perception of available strategic actions.

Our findings are aligned with the finding of Judge and Ilies (2002), who maintained that an individual with a more positive self-image is more motivated to perform a particular behaviour. In contrast to other studies (Judge and Ilies, 2002; Hiller and Hambrick, 2005;

\begin{tabular}{|c|c|c|c|c|}
\hline Variable & 1 & 2 & 3 & \\
\hline $\begin{array}{l}\text { 1. } \text { PSI }^{a} \\
\text { 2. Attitude }{ }^{\mathrm{a}} \text { towards MIS implementation } \\
\text { 3. Level of support }{ }^{\mathrm{a}} \text { towards MIS implementation } \\
\text { M } \\
\text { SD }\end{array}$ & $\begin{array}{l}1 \\
0.537^{* *} \\
0.501^{* *} \\
2.646 \\
0.415\end{array}$ & $\begin{array}{l}1 \\
0.642 * * \\
2.471 \\
0.599\end{array}$ & $\begin{array}{l}1 \\
2.471 \\
0.578\end{array}$ & $\begin{array}{r}\text { Table } 6 . \\
\text { Descriptive statistics } \\
\text { and Pearson }\end{array}$ \\
\hline Notes: $* * p<0.01$. average & & & & correlations \\
\hline
\end{tabular}

\begin{tabular}{llccr}
\hline & \multicolumn{2}{c}{ Hypotheses } & \multicolumn{2}{c}{$\begin{array}{c}\text { Standardised parameter estimates } \\
\text { Estimates }\end{array}$} \\
Linkages in the model & Number & Sign & -value \\
\hline PSI $\rightarrow$ attitude & $H 1$ & + & 0.869 & $6.881^{*}$ \\
Attitude $\rightarrow$ support & $H 2 a$ & + & 0.931 & $9.552^{*}$ \\
PSI $\rightarrow$ attitude $\rightarrow$ support & $H 2 b$ & & $1.65^{*}$ &
\end{tabular}

Notes: Model diagnostic: Chi-square $=72.446(p<0.001)$; degree of freedom $=42 ; \mathrm{GFI}=0.969$; RMSEA $=$ $0.043 ; \mathrm{CFI}=0.973 ; \mathrm{TLI}=0.64 ; * p<0.001$

Table 7. Structural model 


\section{VJIKMS}

\begin{tabular}{lllllllllllll}
\hline Variable & 1 & 2 & 3 & 4 & 5 & 6 & 7 & 8 & 9 & 10 & 11 & 12 \\
\hline 1.PSI & 1 & & & & & & & & & & & \\
2.Attitude & 0.869 & 1 & & & & & & & & & & \\
3.Support & 0.809 & 0.931 & 1 & & & & & & & & & \\
4.Support5(S5) & 0.524 & 0.603 & 0.648 & 1 & & & & & & & & \\
5.Support3(S3) & 0.559 & 0.642 & 0.690 & 0.447 & 1 & & & & & & & \\
6.Support2(S2) & 0.519 & 0.597 & 0.641 & 0.416 & 0.443 & 1 & & & & & & \\
7.Support1(S1) & 0.512 & 0.589 & 0.633 & 0.410 & 0.437 & 0.406 & 1 & & & & & \\
8.Attitude4(A4) & 0.595 & 0.685 & 0.637 & 0.413 & 0.440 & 0.409 & 0.403 & 1 & & & & \\
9.Attitude3(A3) & 0.568 & 0.653 & 0.608 & 0.394 & 0.420 & 0.390 & 0.385 & 0.447 & 1 & & & \\
10.Attitude1(A1) & 0.540 & 0.621 & 0.578 & 0.375 & 0.399 & 0.371 & 0.366 & 0.425 & 0.406 & 1 & & \\
11.PSI1 & 0.495 & 0.430 & 0.400 & 0.259 & 0.276 & 0.257 & 0.253 & 0.294 & 0.281 & 0.267 & 1 & \\
12.PSI2 & 0.708 & 0.615 & 0.573 & 0.371 & 0.395 & 0.367 & 0.362 & 0.421 & 0.402 & 0.382 & 0.350 & 1
\end{tabular}

Standardised pattern coefficients (correlations) for measured and latent variables

Notes: PSI (CSE scale); PSI1 (CSE scale parcel 1); PSI2 (CSE scale parcel 2); MIS implementation Value (A1); efficiency for MIS implementation (A3); organisational benefits (A4); readiness to put effort (S1); effective management strategies (S2); favouring MIS implementation (S3); active involvement (S5)

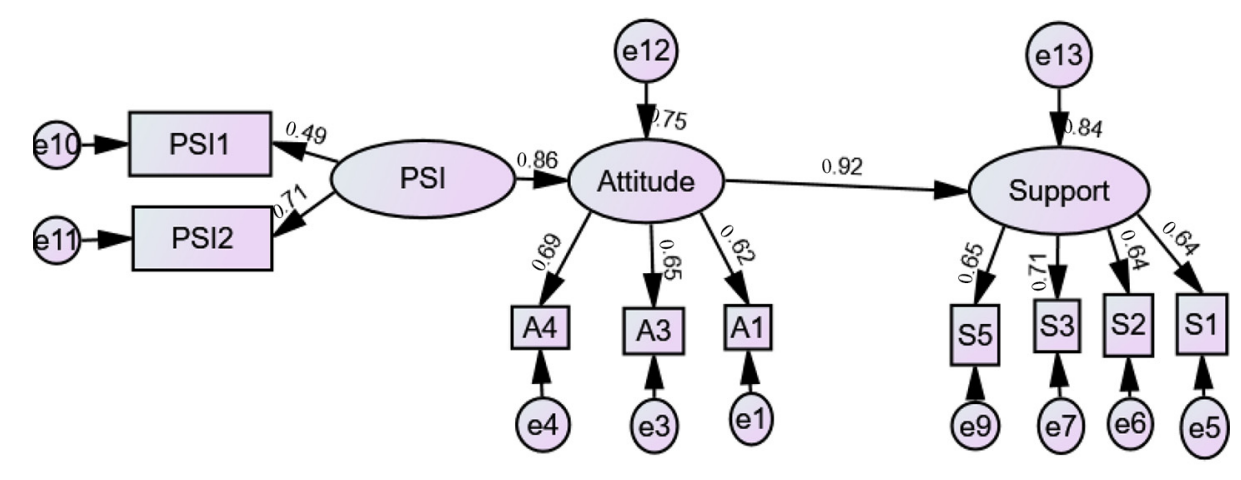

Figure 2.

Structural equation model
Notes: PSI (CSE scale); MIS implementation Value (A1); efficiency for MIS implementation (A3); organisational benefits (A4); readiness to put effort (S1); effective management strategies (S2); favouring MIS implementation (S3); active involvement (S5)

Wang et al., 2016), our study used item-parcelling to analyse the construct of positive selfimage which provides more stable estimates and a more efficient model (Matsunaga, 2008). Judge and Ilies (2002) investigated the relationship between the FFM of personality and an individual's performance motivation. They found that Neuroticism (emotional stability) and Conscientiousness were significant predictors of performance motivation. Our results are similar to their findings because they also showed that a positive self-image has an influence on how a person behaves.

Our findings are similar to the work of Hiller and Hambrick (2005), as they both identified that senior managers' self-image impacts their behaviour. However, our research differs from theirs in that they used an indirect approach to measure CSE whilst we used a direct approach of measuring CSEs. They found that the personalities of senior executives impact their understandings of situations and their decision-making. Our findings are in line with theirs that personality traits of senior managers impact their attitude. Hiller and 
Hambrick (2005) maintained that chief executive officers (CEOs) usually have higher CSE than the general population and have suggested that those at the higher end of the CSE scale could be described as having "executive hubris". In our study, we attempted to identify individuals at the higher end of the CSE scale by rewording some of the statements in our questionnaire that related to CSE. The result showed that CSE ranged from 1.08 to 3.67, with a mean of 2.64 and a standard deviation of 0.414 . It would be worth creating a criterion which distinguishes hubris from high CSE for future research.

Our findings are aligned with the work Wang et al. (2016) which posits that the positive self-image of CEOs is significantly associated with their strategic actions. They used CSE, the FFM of personality and HEXACO taxonomy to measure positive self-image. They found that CEOs with a more positive self-image tend to take more strategic risks which is similar to our result that found that an individual with a more positive self-image has a more positive attitude to taking strategic actions like MIS implementation.

Our study and findings contribute to the upper echelon tradition in several ways and has identified possible future research possibilities. The study presents one of the first empirical tests investigating the impact of personality traits on the support of MIS implementation. Previous studies mostly investigate the impact of personality traits on the strategic decisionmaking or performance of a firm (Boone and Hendriks, 2009).

Erez and Judge (2001) investigated the impact of CSE on motivation and performance. They used an indirect approach to measure CSE in which they measured four traits of CSE separately on three different samples. They put forward that CSE is a predictor of motivation and performance. Boone and Hendriks (2009) looked at the TMT rather than looking at senior managers or CEOs. They argued that TMT diversity has an influence on financial performance through the moderating effect of three team mechanisms (collaborative behaviour, accurate information exchange and decision-making decentralisation). They focussed on functional-background and LOC to distinguish TMT diversity. They used the Rotter scale (Rotter, 1966) to measure LOC whilst we use the whole concept of CSE.

By investigating senior managers' positive self-image, we extend upper echelon research which has in the past almost exclusively focussed on demographic characteristics (e.g. age, tenure, education). In their study, Carpenter et al. (2001) argued that the international experience of CEOs impacts their performance in international organisations. However, they did not look into the correlations between the psychological traits of senior managers and their performance.

In addition to the main contribution of our study, we looked at the impact of self-image on the attitude of senior managers. Our study further investigates how senior managers' positive self-image can influence their support towards MIS implementation through their attitude. We found that a senior manager who had a positive self-image was more enthusiastic and supportive in implementing MIS. By investigating self-image, UET is extended in comparison with other studies who limited their research to the use of only demographic characteristics. So, in the future, those carrying out research in this area should consider traits such as self-image and their impact.

\section{Implications}

The research can be considered as significant because it may assist managers in implementing MIS to improve organisational efficiencies. Studies like ours are often used by senior managers in national and international organisations to analyse the effective implementation of MIS (Laumer et al., 2017). MIS is crucial in companies as it helps them to improve their efficiency and achieve organisational success (Padek et al., 2018; Thiesse et al., 
2015). Having found in our study that senior managers attitude towards MIS implementation varies according to their positive self-image our research could be used by senior managers to self-assess how they would perform when implementing MIS.

Previous research has shown that personality characteristics such as positive self-image influences the intention to behave (Joshi et al., 2016; Iden and Eikebrokk, 2015). Senior managers also effectively assess their values because it is considered as one of the most compelling attributes in a manager (Dust et al., 2020). Therefore, our research may assist senior managers to shape organisational behaviours through their values. The research in beneficial to organisations because it provides insights about the attitude and behaviour of senior managers and the support they give in the implementation of MIS. The research specifically focussed on the implementation of MIS in the manufacturing industry, which is also beneficial for manufacturing organisations on a global scale (Laumer et al., 2017; Thiesse et al., 2015).

\section{Limitations}

Our research was conducted by evaluating the factors that influence the support managers to provide in implementing MIS. We found that the scales are valid in the manufacturing industry in the UK, but they need to be validated in other industries and countries, Data collection was limited because it was obtained via a questionnaire. Further study in this area could be carried out by collecting data through qualitative methods such as interviews with senior managers of the manufacturing firms. This would allow an in-depth analysis of the participants' behaviour and experiences. This research has dealt with the impact of senior managers' positive self-image on their support towards MIS implementation but does not focus on MIS implications. A further study with more focus on MIS implications, therefore, is suggested. Moreover, this study focussed on ERP, CRM and SRM, future research may be conducted on other MISs. There is abundant room for further progress in studying the various number of risks and rewards associated with MIS implementation.

\section{Future research and conclusion}

Our research has shown a gap in our understanding of the factors that influence the effectiveness of senior managers in implementing MIS. To narrow this gap, future research might use different measures to quantify positive self-image and use internal and external LOC. In addition to the personality traits of senior managers, it might also look at demographic factors that influence their effectiveness. These would include age, education, prior career experience and prior involvement with IS projects. We feel highly motivated to carry out the necessary research that will further illuminate this topic and provide practical suggestions for how companies and organisation can improve the efficiency with which they implement IS.

This research has demonstrated the importance of the psychological attributes of senior managers and their positive attitude in ensuring the effective implementation of MIS. Our study recommends that senior managers assess their personality characteristics and reflect on how their attitude impacts their actions. A senior manager's self-awareness markedly influences their support during the implementation process.

\section{References}

Abatecola, G. and Cristofaro, M. (2020), "Hambrick and Mason's 'upper Echelons theory': evolution and open avenues”, Journal of Management History, Emerald Group Publishing Ltd., Vol. 26 No. 1, pp. 116-136, doi: 10.1108/JMH-02-2018-0016. 
Agarwal, D. and Garg, P. (2012), "ERP implementation in hospitals: a case study", International Journal of Electronic Healthcare, Vol. 7 No. 2, p. 157, doi: 10.1504/IJEH.2012.049876.

Ajzen, I. (1991), "The theory of planned behavior", Organizational Behavior and Human Decision Processes, Vol. 50 No. 2, pp. 179-211, doi: 10.1016/0749-5978(91)90020-T.

Ajzen, I. and Fishbein, M. (1975), "A Bayesian analysis of attribution processes”, Psychological Bulletin, Vol. 82 No. 2, pp. 261-277, doi: 10.1037/h0076477.

Ajzen, I. and Fishbein, M. (1977), "Attitude-behavior relations: a theoretical analysis and review of empirical research", Psychological Bulletin, Vol. 84 No. 5, pp. 888-918, doi: 10.1037/00332909.84.5.888.

Ali, M. and Miller, L. (2017), "ERP system implementation in large enterprises - a systematic literature review", Journal of Enterprise Information Management, Vol. 30 No. 4, doi: 10.1108/JEIM-072014-0071.

Almajali, D.A., Masa'deh, R. and Tarhini, A. (2016), "Antecedents of ERP systems implementation success: a study on Jordanian healthcare sector", Journal of Enterprise Information Management, Vol. 29 No. 4, pp. 549-565, doi: 10.1108/JEIM-03-2015-0024.

Amid, A., Moalagh, M. and Zare Ravasan, A. (2012), "Identification and classification of ERP critical failure factors in Iranian industries", Information Systems, Vol. 37 No. 3, pp. 227-237, doi: $10.1016 /$ j.is.2011.10.010.

Anderson, J.C. and Gerbing, D.W. (1988), "Structural equation modeling in practice: a review and recommended two-step approach", Psychological Bulletin, Vol. 103 No. 3, pp. 411-423.

Bandalos, D.L. (2014), "Relative performance of categorical diagonally weighted least squares and robust maximum likelihood estimation", Structural Equation Modeling: A Multidisciplinary Journal, Vol. 21 No. 1, pp. 102-116.

Barlow, D.H., Ellard, K.K., Sauer-Zavala, S., Bullis, J.R. and Carl, J.R. (2014), "The origins of neuroticism”, Perspectives on Psychological Science, Vol. 9 No. 5, pp. 481-496, doi: 10.1177/ 1745691614544528.

Barrick, M.R., Mount, M.K. and Gupta, R. (2003), "Meta-analysis of the relationship between the fivefactor model of personality and Holland's occupational types", Personnel Psychology, Vol. 56 No. 1, pp. 45-74, doi: 10.1111/j.1744-6570.2003.tb00143.x.

Baruch, Y. (1999), "Response rate in academic studies - a comparative analysis", Human Relations, SAGE Publications Ltd, Vol. 52 No. 4, pp. 421-438, doi: 10.1177/001872679905200401.

Besar, S.S.N.T., Ali, M.M. and Ghani, E.K. (2017), "Examining upper echelons managers' characteristics on financial restatements", Journal of International Studies, Vol. 10 No. 4, pp. 179-191, doi: 10.14254/2071-8330.2017/10-4/14.

Bessen, J. (2017), "Information technology and industry concentration”, Boston University School of Law, Law and Economics Paper No. 17-41, (17), p. 43, available at: www.bu.edu/law/facultyscholarship/working-paper-series/ (accessed 24 May 2021).

Boone, C. and Hendriks, W. (2009), "Top management team diversity and firm performance: moderators of functional-background and locus-of-control diversity", Management Science, Vol. 55 No. 2, pp. 165-180, doi: 10.1287/mnsc.1080.0899.

Bozeman, D.P. and Perrewé, P.L. (2001), "The effect of item content overlap on organizational commitment questionnaire-turnover cognitions relationships", Journal of Applied Psychology, Vol. 86 No. 1, pp. 161-173, doi: 10.1037/0021-9010.86.1.161.

Brown, D.J., Ferris, D.L., Heller, D. and Keeping, L.M. (2007), "Antecedents and consequences of the frequency of upward and downward social comparisons at work", Organizational Behavior and Human Decision Processes, Vol. 102 No. 1, pp. 59-75, doi: 10.1016/j.obhdp.2006.10.003.

Buer, S.V., Strandhagen, J.W., Semini, M. and Strandhagen, J.O. (2020), "The digitalization of manufacturing: investigating the impact of production environment and company size", Journal of Manufacturing Technology Management, Vol. 32 No. 3, doi: 10.1108/JMTM-05-2019-0174. 
Byrne, B. (2012), Structural Equation Modeling with Mplus: Basic Concepts, Applications, and Programming, Taylor and Francis.

Carpenter, M.A., Sanders, W.G. and Gregersen, H.B. (2001), "Bundling human capital with organizational context: the impact of international assignment experience on multinational firm performance and CEO pay", Academy of Management Journal, Vol. 44 No. 3, pp. 493-511, doi: 10.2307/3069366.

Cattell, R.B. (1965), The Scientific Analysis of Personality, Penguin, Baltimore, MD.

Chang, C.-H., Lance Ferris, D., Johnson, R.E., Rosen, C.C. and Tan, J.A. (2012), "Core self-evaluations: a review and evaluation of the literature", Journal of Management, Vol. 38 No. 1, pp. 81-128, doi: 10.1177/0149206311419661.

Chatterjee, S., Ghosh, S.K. and Chaudhuri, R. (2020), "Knowledge management in improving business process: an interpretative framework for successful implementation of AI-CRM-KM system in organizations", Business Process Management Journal, Vol. 26 No. 6, pp. 1261-1281, doi: 10.1108/ BPMJ-05-2019-0183.

Costa, P.T. and McCrae, R.R. (1992), "The five-factor model of personality and its relevance to personality disorders", Journal of Personality Disorders, Vol. 6 No. 4, pp. 343-359, doi: 10.1521/ pedi.1992.6.4.343.

Cruz-Jesus, F., Pinheiro, A. and Oliveira, T. (2019), "Understanding CRM adoption stages: empirical analysis building on the TOE framework", Computers in Industry, Vol. 109, pp. 1-13, doi: 10.1016/j.compind.2019.03.007.

Di Fabio, A. and Kenny, M.E. (2016), "From decent work to decent lives: positive self and relational management (PS\&RM) in the twenty-first century", Frontiers in Psychology, Vol. 7, p. 361.

Dichev, I.D. and Skinner, D.J. (2002), "Large-sample evidence on the debt covenant hypothesis", Journal of Accounting Research, Vol. 40 No. 4, pp. 1091-1123, doi: 10.1111/1475-679X.00083.

Dust, S., Rode, J. and Wang, P. (2020), "Leader self-enhancement values: curvilinear and congruence effects", Leadership and Organization Development Journal, Vol. 41 No. 5, pp. 687-701, doi: 10.1108/LODJ-102019-0438.

Ehie, I.C. and Madsen, M. (2005), "Identifying critical issues in enterprise resource planning (ERP) implementation”, Computers in Industry, Vol. 56 No. 6, pp. 545-557, doi: 10.1016/j.compind.2005.02.006.

Elbanna, A. (2013), “Top management support in multiple-project environments: an in-practice view”, European Journal of Information Systems, Vol. 22 No. 3, pp. 278-294.

Erez, A. and Judge, T.A. (2001), "Relationship of core self-evaluations to goal setting, motivation, and performance", Journal of Applied Psychology, American Psychological Association Inc., Vol. 86 No. 6, pp. 1270-1279, doi: 10.1037/0021-9010.86.6.1270.

Evert, R.E., Payne, G.T., Moore, C.B. and McLeod, M.S. (2018), “Top management team characteristics and organizational virtue orientation: an empirical examination of IPO firms", Business Ethics Quarterly, Vol. 28 No. 4, pp. 427-461.

Farrar, S., Stopa, L. and Turner, H. (2015), "Self-imagery in individuals with high body dissatisfaction: the effect of positive and negative self-imagery on aspects of the self-concept", Journal of Behavior Therapy and Experimental Psychiatry, Vol. 46, pp. 8-13.

Finkelstein, S. (1992), "Power in top management teams: dimensions, measurement, and validation", Academy of Management Journal, Vol. 35 No. 3, pp. 505-538.

Finkelstein, S., Hambrick, D.C. and Cannella, S. (2009), Strategic Leadership: Theory and Research on Executives, Top Management Teams, and Boards, Oxford University Press.

Fishbein, M. and Ajzen, I. (2010), Predicting and Changing Behavior: The Reasoned Action Approach, Taylor and Francis Group.

Galliers, R.D. and Currie, W.L. (2011), The Oxford Handbook of Management Information Systems: Critical Perspectives and New Directions, Oxford University Press, doi: 10.1093/oxfordhb/ 9780199580583.001.0001. 
Gardner, D.G. and Pierce, J.L. (2010), "The core self-evaluation scale: further construct validation evidence", Educational and Psychological Measurement, Vol. 70 No. 2, pp. 291-304, doi: 10.1177/ 0013164409344505.

Grant, S.B. (2016), "Classifying emerging knowledge sharing practices and some insights into antecedents to social networking: a case in insurance", Journal of Knowledge Management, Vol. 20 No. 5, pp. 898-917, doi: 10.1108/JKM-11-2015-0432.

Grant, S.B. and Preston, T.A. (2019), "Using social power and influence to mobilise the supply chain into knowledge sharing: a case in insurance", Information and Management, Vol. 56 No. 5, pp. 625-639, doi: 10.1016/j.im.2018.10.004.

Guerola-Navarro, V., Oltra-Badenes, R., Gil-Gomez, H. and Iturricha Fernández, A. (2021), "Customer relationship management $(\mathrm{CRM})$ and innovation: a qualitative comparative analysis $(\mathrm{QCA})$ in the search for improvements on the firm performance in winery sector", Technological Forecasting and Social Change, Vol. 169, p. 120838, doi: 10.1016/j.techfore.2021.120838.

Hair, J.F., Black, W.C., Babin, B.J. and Anderson, R.E. (2010), Multivariate Data Analysis, 7th ed., Prentice Hall, Upper Saddle River, NJ.

Hair, J.F., L.D.S. Gabriel, M., da Silva, D. and Braga Junior, S. (2019a), "Development and validation of attitudes measurement scales: fundamental and practical aspects", RAUSP Management Journal, Vol. 54 No. 4, pp. 490-507, doi: 10.1108/RAUSP-05-2019-0098.

Hair, J.F., Risher, J.J., Sarstedt, M. and Ringle, C.M. (2019b), "When to use and how to report the results of PLS-SEM", European Business Review, Vol. 31 No. 1, pp. 2-24, doi: 10.1108/EBR-11-2018-0203.

Hambrick, D.C. (2007), "Upper Echelons thoery: an update", Academy of Management Review, Vol. 32 No. 2, pp. 334-343, doi: 10.5465/AMR.2007.24345254.

Hambrick, D.C. and Mason, P.A. (1984), "Upper Echelons: the organization as a reflection of its top managers", Academy of Management Review, Vol. 9 No. 2, pp. 193-206, doi: 10.5465/ AMR.1984.4277628.

Hiebl, M.R.W. (2014), "Upper Echelons theory in management accounting and control research", Journal of Management Control, Vol. 24, pp. 223-240, doi: 10.1007/s00187-013-0183-1.

Hill, A.D., Petrenko, O.V., Ridge, J.W. and Aime, F. (2019), "Videometric measurement of individual characteristics in difficult to access subject pools: demonstrating with CEOs", Research Methodology in Strategy and Management, Vol. 11, pp. 39-61, doi: 10.1108/S1479838720190000011005.

Hiller, N.J. and Hambrick, D.C. (2005), "Conceptualizing executive hubris: the role of (hyper-) core selfevaluations in strategic decision-making", Strategic Management Journal, Vol. 26 No. 4, pp. 297-319, doi: 10.1002/smj.455.

Iacovou, C.L. and Nakatsu, R. (2008), "A risk profile of offshore-outsourced development projects", Communications of the ACM, Vol. 51 No. 6, pp. 89-94, doi: 10.1145/1349026.1349044.

IDC (2018), IDC FutureScape: Worldwide IT Industry 2019 Predictions.

Iden, J. and Eikebrokk, T.R. (2015), "The impact of senior management involvement, organisational commitment and group efficacy on ITIL implementation benefits", Information Systems and eBusiness Management, Springer Verlag, Vol. 13 No. 3, pp. 527-552, doi: 10.1007/s10257-014-0253-4.

Jarvenpaa, S.L. and Ives, B. (1991), "Executive involvement and participation in the management of information technology", MIS Quarterly, Vol. 15 No. 2, p. 205, doi: 10.2307/249382.

Jha, V.K. and Pal, P. (2016), "Literature review on ERP implementation challenges", International Journal of Business Information Systems, Vol. 21 No. 3, pp. 388-402, doi: 10.1504/IJBIS.2016.074766.

Johnson, R.E., Rosen, C.C. and Levy, P.E. (2008), "Getting to the core of core self-evaluation: a review and recommendations", Journal of Organizational Behavior, Vol. 29 No. 3, pp. 391-413, doi: $10.1002 /$ job.514.

Joshi, P., Kaur, H. and Jain, A. (2016), "Leadership behaviour of manager: an antecedent of job satisfaction of subordinates", SCMS Journal of Indian Management, pp. 19-32, available at: 
http://search.proquest.com/openview/bc229c6d39dd26f21d7408de5569b183/1?pq-origsite=gscholar\& $\mathrm{cbl}=546310$ (accessed 26 October 2020).

Judge, T.A. and Ilies, R. (2002), "Relationship of personality to performance motivation: a meta-analytic review”, Journal of Applied Psychology American Psychological Association Inc., Vol. 87 No. 4, pp. 797-807, doi: 10.1037/0021-9010.87.4.797.

Judge, T.A., Erez, A., Bono, J.E. and Thoresen, C.J. (2002), "Are measures of self-esteem, neuroticism, locus of control, and generalized self-efficacy indicators of a common core construct?", Journal of Personality and Social Psychology, Vol. 83 No. 3, pp. 693-710, doi: $10.1037 / 0022-3514.83 .3 .693$.

Judge, T.A., Erez, A., Bono, J.E. and Thoresen, C.J. (2003), “The core self-evaluations scale: development of a measure", Personnel Psychology, Vol. 56 No. 2, pp. 303-331, doi: 10.1111/j.1744-6570.2003. tb00152.x.

Kamer, B. and Annen, H. (2010), "The role of core self-evaluations in predicting performance appraisal reactions", Swiss Journal of Psychology, Vol. 69 No. 2, pp. 95-104, doi: 10.1024/ 1421-0185/a000011.

Kappelman, L.A., McKeeman, R. and Zhang, L. (2006), "Early warning signs of IT project failure: the dominant dozen”, Information Systems Management, Vol. 23 No. 4, pp. 31-36, doi: 10.1201/ 1078.10580530/46352.23.4.20060901/95110.4.

Khan, S.A., Lederer, A.L. and Mirchandani, D.A. (2013), "Top management support, collective mindfulness, and information systems performance", Journal of International Technology and Information Management, Vol. 22 No. 1, pp. 95-122.

Kishton, J.M. and Widaman, K.F. (1994), "Unidimensional versus domain representative parceling of questionnaire items: an empirical example", Educational and Psychological Measurement, Sage Publications, Thousand Oaks, CA, Vol. 54 No. 3, pp. 757-765, doi: 10.1177/0013164494054003022.

Kwok, S.H. and Gao, S. (2005), "Attitude towards knowledge sharing behavior", Journal of Computer Information Systems, Vol. 46 No. 2, pp. 45-51, doi: 10.1080/08874417.2006.11645882.

Lam, T., Cho, V. and Qu, H. (2007), "A study of hotel employee behavioral intentions towards adoption of information technology", International Journal of Hospitality Management, Vol. 26 No. 1, pp. 49-65, doi: 10.1016/j.ijhm.2005.09.002.

Landis, R.S., Beal, D.J. and Tesluk, P.E. (2000), "A comparison of approaches to forming composite measures in structural equation models", Organizational Research Methods, SAGE Publications, Vol. 3 No. 2, pp. 186-207, doi: 10.1177/109442810032003.

Laudon, K.C. and Laudon, J.P. (2020), Management Information Systems: Managing the Digital Firm, 16 th ed., Pearson.

Laumer, S., Maier, C. and Weitzel, T. (2017), "Information quality, user satisfaction, and the manifestation of workarounds: a qualitative and quantitative study of enterprise content management system users", European Journal of Information Systems, Palgrave Macmillan Ltd., Vol. 26 No. 4, pp. 333-360, doi: 10.1057/s41303-016-0029-7.

Ledgerwood, A. and Shrout, P.E. (2011), "The trade-off between accuracy and precision in latent variable models of mediation processes", Journal of Personality and Social Psychology, Vol. 101 No. 6, pp. 1174-1188, doi: 10.1037/a0024776.

Lin, H.F. (2010), "An investigation into the effects of is quality and top management support on ERP system usage”, Total Quality Management and Business Excellence, Vol. 21 No. 3, pp. 335-349.

López-Muñoz, J.F. and Escribá-Esteve, A. (2017), An upper echelons perspective on information technology business value, European Research on Management and Business Economics.

Mullins, J.K. and Cronan, T.P. (2021), "Enterprise systems knowledge, beliefs, and attitude: a model of informed technology acceptance", International Journal of Information Management, Vol. 59, p. 102348, doi: 10.1016/j.ijinfomgt.2021.102348. 
Ndofirepi, T.M. (2020), "Relationship between entrepreneurship education and entrepreneurial goal intentions: psychological traits as mediators", Journal of Innovation and Entrepreneurship, Vol. 9 No. 1, doi: 10.1186/s13731-020-0115-x.

Padek, M., Allen, P., Erwin, P.C., Franco, M., Hammond, R.A., Heuberger, B., Kasman, M., Luke, D.A., Mazzucca, S., Moreland-Russell, S. and Brownson, R.C. (2018), "Toward optimal implementation of cancer prevention and control programs in public health: a study protocol on mis-implementation", Implementation Science, BioMed Central Ltd., Vol. 13 No. 1, p. 49, doi: 10.1186/s13012-018-0742-9.

Pallant, J. (2011), SPSS Survival Manual; a Step by Step Guidance to Data Analysis Using SPSS, 4th ed., Routledge.

Peixoto, F. and Almeida, L.S. (2010), "Self-concept, self-esteem and academic achievement: strategies for maintaining self-esteem in students experiencing academic failure", European Journal of Psychology of Education, Vol. 25 No. 2, pp. 157-175.

Poba-Nzaou, P., Raymond, L. and Fabi, B. (2008), "Adoption and risk of ERP systems in manufacturing SMEs: a positivist case study”, Business Process Management Journal, Vol. 14 No. 4, pp. 530-550, doi: 10.1108/14637150810888064.

Quazi, A. and Talukder, M. (2011), "Demographic determinants of adoption of technological innovation", Journal of Computer Information Systems, Vol. 52 No. 1, pp. 34-42, doi: 10.1080/ 08874417.2011.11645520.

Rosenberg, M. (1965), Society and the Adolescent Self-Image, Princeton University Press, Princeton, NJ.

Roumani, Y., Nwankpa, J.K. and Roumani, Y.F. (2017), "Adopters' trust in enterprise open source vendors: an empirical examination", Journal of Systems and Software, Vol. 125, pp. 256-270, doi: 10.1016/J.JSS.2016.12.006.

Saunders, A. and Brynjolfsson, E. (2016), "Valuing information technology related intangible assets", MIS Quarterly, Vol. 40 No. 1, pp. 83-110, doi: 10.25300/MISQ/2016/40.1.04.

Seo, E., Shen, Y. and Benner, A.D. (2019), "The paradox of positive self-concept and low achievement among Black and Latinx youth: a test of psychological explanations", Contemporary Educational Psychology, Vol. 59, p. 101796.

Shaul, L. and Tauber, D. (2013), "Critical success factors in enterprise resource planning systems", ACM Computing Surveys, Vol. 45 No. 4, pp. 1-39, doi: 10.1145/2501654.2501669.

Somers, T.M. and Nelson, K. (2001), "The impact of critical success factors across the stages of enterprise resource planning implementations", Proceedings of the HI International Conference on System Sciences, IEEE Comput. Soc, p. 215, doi: 10.1109/HICSS.2001.927129.

Tandon, A., Dhir, A., Kaur, P., Kushwah, S. and Salo, J. (2020), "Behavioral reasoning perspectives on organic food purchase”, Appetite, Vol. 154, p. 104786, doi: 10.1016/j. appet.2020.104786.

Thiesse, F., Wirth, M., Kemper, H.G., Moisa, M., Morar, D., Lasi, H., Piller, F., Buxmann, P., Mortara, L., Ford, S. and Minshall, T. (2015), "Economic implications of additive manufacturing and the contribution of MIS", Business and Information Systems Engineering, Gabler Verlag, Vol. 57 No. 2, pp. 139-148, doi: 10.1007/s12599-015-0374-4.

Vieru, D. and Rivard, S. (2014), "Organizational identity challenges in a post-merger context: a case study of an information system implementation project", International Journal of Information Management, Vol. 34 No. 3, pp. 381-386, doi: 10.1016/j.ijinfomgt.2014.02.001.

Wagner, E. and Newell, S. (2011), "Changing the story surrounding enterprise systems to improve our understanding of what makes ERP work in 'organizations", The Oxford Handbook of Management Information Systems: Critical Perspectives and New Directions, Oxford University Press, doi: 10.1093/oxfordhb/9780199580583.003.0018.

Wang, G., Holmes, R.M., Oh, I.S. and Zhu, W. (2016), "Do CEOs matter to firm strategic actions and firm performance? A meta-analytic investigation based on upper echelons theory", Personnel Psychology, Vol. 69 No. 4, pp. 775-862, doi: 10.1111/peps.12140. 
Weng, Q. and McElroy, J.C. (2010), "Vocational self-concept crystallization as a mediator of the relationship between career self-management and job decision effectiveness", Journal of Vocational Behavior, Vol. 76 No. 2, pp. 234-243.

Wilt, J. and Revelle, W. (2009), "Extraversion", Handbook of Individual Differences in Social Behavior, The Guilford Press, pp. 27-45.

Xu, L., Du, J., Lei, X. and Hipel, K.W. (2020), "Effect of locus of control on innovative behavior among new generation employees: a moderated mediation model", Social Behavior and Personality, Scientific Journal Publishers, Vol. 48 No. 10, doi: 10.2224/SBP.9379.

Young, R. and Jordan, E. (2008), “Top management support: mantra or necessity?", International Journal of Project Management, Vol. 26 No. 7, pp. 713-725, doi: 10.1016/j. ijproman.2008.06.001.

\section{Further reading}

Aggarwal, J. and Krishnan, V.R. (2013), "Impact of transformational leadership on follower's selfefficacy: moderating role of follower's impression management", Management and Labour Studies, Vol. 38 No. 4, pp. 297-313.

Arthur, W., Jr, Bennett, W., Jr and Huffcutt, A.I. (2001), Conducting Meta-Analysis Using SAS, Lawrence Erlbaum, Mahwah, NJ.

Boonstra, A. (2013), "How do top managers support strategic information system projects and why do they sometimes withhold this support?", International Journal of Project Management, Vol. 31 No. 4, pp. 498-512.

Chamorro-Premuzic, T., Ahmetoglu, G. and Furnham, A. (2008), "Little more than personality: dispositional determinants of test anxiety (the big five, core self-evaluations, and self-assessed intelligence)", Learning and Individual Differences, Vol. 18 No. 2, pp. 258-263.

Dong, L., Neufeld, D. and Higgins, C. (2009), "Top management support of enterprise systems implementations", Journal of Information Technology, Vol. 24 No. 1, pp. 55-80.

Fountas, S., Sorensen, C.G., Tsiropoulos, Z., Cavalaris, C., Liakos, V. and Gemtos, T. (2015), "Farm machinery management information system", Computers and Electronics in Agriculture, Vol. 110, pp. 131-138.

Inglés, C.J., Martínez-González, A.E., García-Fernández, J.M., Torregrosa, M.S. and Ruiz Esteban, C. (2012), "Prosocial behavior and self-concept of Spanish students of compulsory secondary education".

Kithome, V.K. (2012), "Factors influencing implementation of management information system projects in tertiary level academic institutions in Mombasa County, Kenya”, Doctoral dissertation, University of Nairobi, Kenya.

Kraus, M.W., Chen, S. and Keltner, D. (2011), "The power to be me: power elevates self-concept consistency and authenticity", Journal of Experimental Social Psychology, Vol. 47 No. 5, pp. 974-980.

Taş, İ. and İskender, M. (2017), "An examination of meaning in life, satisfaction with life, self-concept and locus of control among teachers", Journal of Education and Training Studies, Vol. 6 No. 1, pp. 21-31.

Wang, C.W. and Neihart, M. (2015), "Academic self-concept and academic self-efficacy: self-beliefs enable academic achievement of twice-exceptional students", Roeper Review, Vol. 37 No. 2, pp. 63-73.

Zopiatis, A. and Constanti, P. (2012), "Extraversion, openness and conscientiousness", Leadership and Organization Development Journal, Vol. 33 No. 1. 


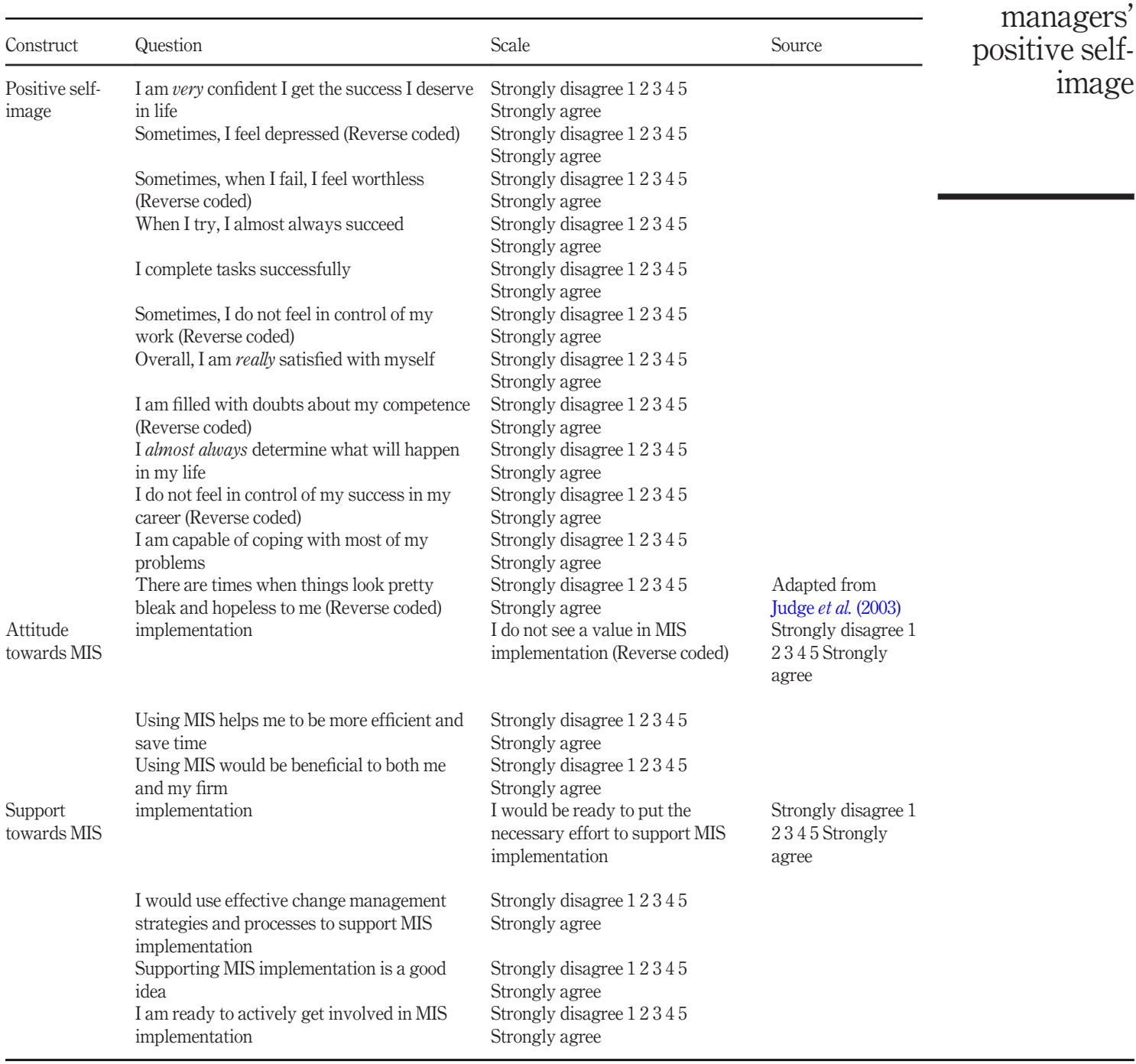

\section{Corresponding author}

Nahid Izadpanah Mehrkish can be contacted at: nahid.izadpanahmehrkish@brunel.ac.uk

For instructions on how to order reprints of this article, please visit our website: 